species is rising. "If the warming trend persists, we will see drastic changes in the ecosystems, with devastating consequences on biodiversity and the livelihood of mountain communities," he adds.

India and Nepal are not the only nations affected. Hindu Kush is a 3,500-kilometre mountain chain that spans eight countries - from Afghanistan to Myanmar. Known as Asia's water tower, the mountains provide ecosystem services and support the livelihoods of more than one-fifth of the global population.

"The impact of climate change is compounded by many other challenges that face the Himalayas," says David Molden, ICIMOD's director general. In the past few decades, the region has seen increasing population growth, energy shortages, pollution, environmental degradation and disasters - all of which challenge traditional livelihoods. "Once self-sufficient people now face dire economic poverty," he says.

To mitigate climate change, it is crucial to factor in all those challenges, says Molden. This is where ICIMOD's assessment comes in. It will, he says, review the current state of knowledge on glaciers, biodiversity, water resources and pollution, identify trends of changes in climate, demography and land use, and address issues such as poverty, hydropower development, natural disasters and food security. The result will be a set of policy recommendations on, for example, sustainable grazing, increased collaboration between nations, deforestation and flood prevention.

The Himalayas are of global significance, says Volker Mosbrugger, director of the Senckenberg Research Institute and Natural History Museum in Frankfurt, Germany. The report will help to manage the region's wealth of resources sustainably and empower mountain communities to tackle climate change, he says.

Pandit lauds the project as "timely and important", but says that it is the enforcement that matters. "Whatever decisions or recommendations are given, they have to reach local authorities." -

1. Shrestha, U. B., Gautam, S. \& Bawa, K. PLoS ONE 7, e36741 (2012)

2. Telwala, Y., Brook, B. W., Manish, K. \& Pandit, M. K. PLOS ONE 8, e57103 (2013).

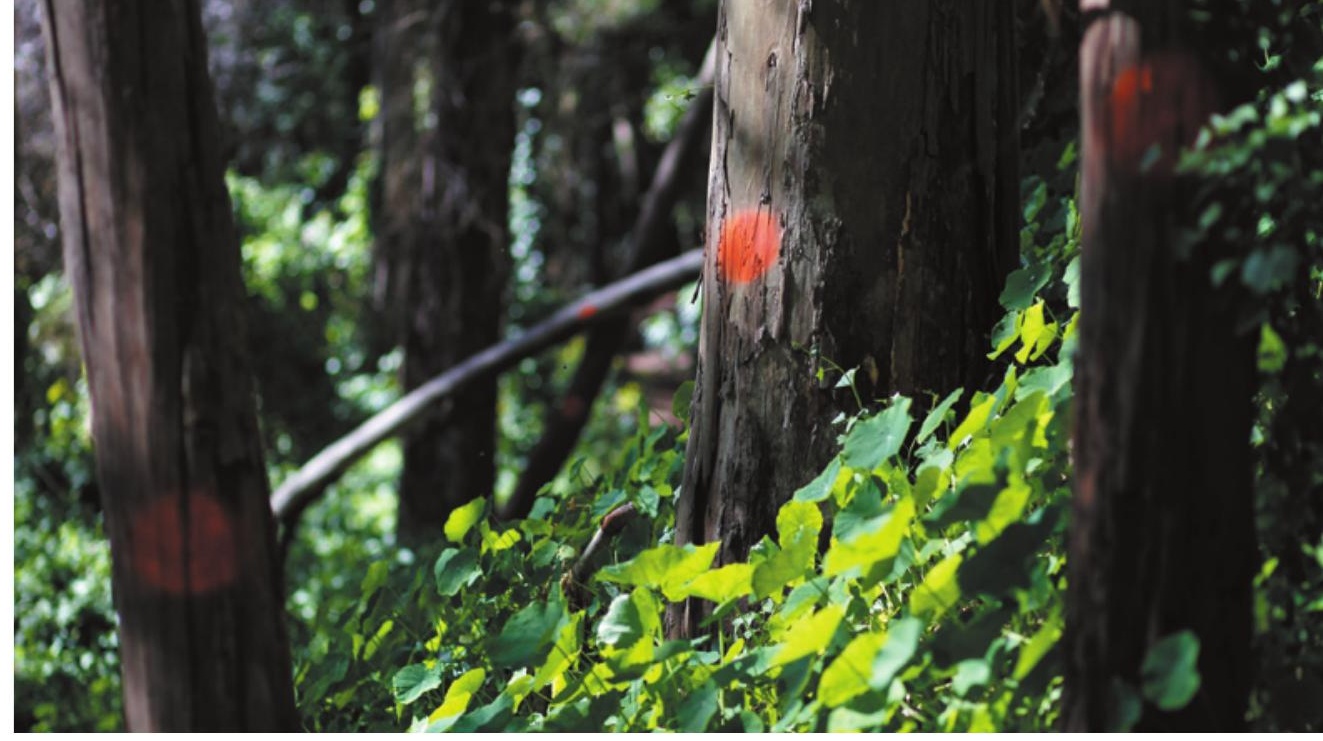

Non-native eucalyptus trees dominate the wild forest that covers San Francisco's Mount Sutro.

ECOLOGY

\title{
Forest management plans in a tangle
}

\section{Conservation fight flares over invasive California eucalyptus.}

\section{BY DANIELLE VENTON}

$\mathrm{I}$ $\mathrm{n}$ the middle of metropolitan San Francisco stands an army — and many Bay Area residents want it to stay garrisoned there. It is a forest of non-native, invasive blue gum eucalyptus, along with Monterey cypress and pine, that has covered the city's Mount Sutro since the late nineteenth century.

For more than a decade, the University of California, San Francisco (UCSF), which sits at the base of the hill and owns the 25-hectare reserve, has sought to manage the forest. Its aim is to reduce fire hazards and to encourage native grasses, wild flowers and brush by selectively thinning the trees. It also wants to restore the original natural habitat - and some conservationists and locals are having none of it.

On 29 August, as San Francisco's characteristic fog burned off, about 40 protesters stood in front of the UCSF campus while a crew with chainsaws and electric weed-cutters cleared blackberry bushes, ivy vines and small eucalyptus trees near roads and buildings in what the university is calling "urgent fire measures" recommended by the city's fire department. The protesters were not pleased to see the trees come down, even in the name of fire safety. "Here we have a beautiful, wild forest right in the middle of our city and the university wants to destroy it," says Paul Rotter, a resident of the area since the 1970s who regularly walks the hill.

Selective tree-clearing on Mount Sutro would help the larger remaining trees to fight the beetle and fungal pests currently afflicting the forest, say UCSF consultants. The area's great horned owls could also have more foraging opportunities. Reducing competition for sunlight should encourage the growth of large trees, which, say consultants, would enhance carbon storage and reduce the risk of the catastrophic fires that threaten lives and property, and pour carbon into the atmosphere.

That these reasons hold little water with the protesters highlights an emerging fissure among environmentalists and ecologists. For some, a hardline devotion to preserving native ecosystems is giving way to a more postmodern idea of what constitutes a natural
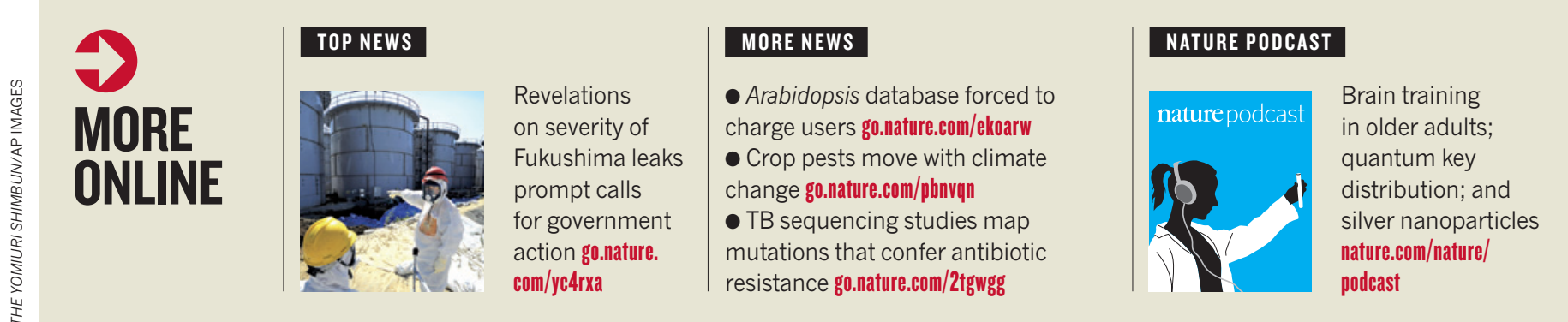
- landscape. "Mount Sutro is part of a larger story," says Richard Hobbs, an ecologist at the University of Western Australia in Crawley. "What some people see as a weed-filled blot on the landscape, others see as something extremely valuable, worthy of managing in its own right. People are increasingly moving away from the belief that a native ecosystem is always best."

That idea grates with many restoration ecologists, says Hobbs. Yet studies increasingly suggest that altered ecosystems need not be bad for biodiversity or ecosystem function. Non-native pine trees provide habitat for threatened cockatoos in Western Australia, for example. And in Scotland, old industrial waste heaps - known as shale bings - are now home to rare and protected plants and animals.

In the early 1990s, Patricia Kennedy of Oregon State University in Corvallis helped to develop management guidelines for northern goshawks. She found that the raptors do not strictly need old-growth forests; land used for timber harvesting can work, too. She says that, at the time, accepting the idea felt like a move to the "dark side". "The whole culture in wildlife biology and conservation circles has been that you can't approximate Mother Nature," she says.

But those ideas are changing today, with altered ecosystems such as Mount Sutro's providing a case in point. In the late 1880 s, Adolph Sutro, a mayor of San Francisco, planted the tree-less hill with imported blue gum eucalyptus, as well as Monterey pine and cypress. The eucalyptus quickly took over, and today the forest feels like a primeval jungle - a tangle of almost exclusively introduced species. Joe Mascaro, an ecologist at Stanford University in California who has been publicly critical of UCSF's management plans, says that Mount Sutro has long since given way to a completely new ecosystem. "Restoring it to an original state would be borderline impossible, so why stop the succession that is already in place?"

Resistance to such a heretical idea runs deep among ecologists, but growing numbers are embracing altered ecosystems in the name of pragmatism. "You can reach more win-win situations if you don't insist on purity," says Katharine Suding, an ecologist at the University of California, Berkeley, who specializes in restoring human-affected areas. "It doesn't have to be a natural versus non-natural dichotomy."

For UCSF, finding a middle ground between native and non-native conservation ideals is proving difficult. But the university should get used to it, says Hobbs.

"There is a lot of tension about how to deal with situations like these right now," he says. "With so much non-native habitat, the old views - that everything must be natural - no longer apply." -

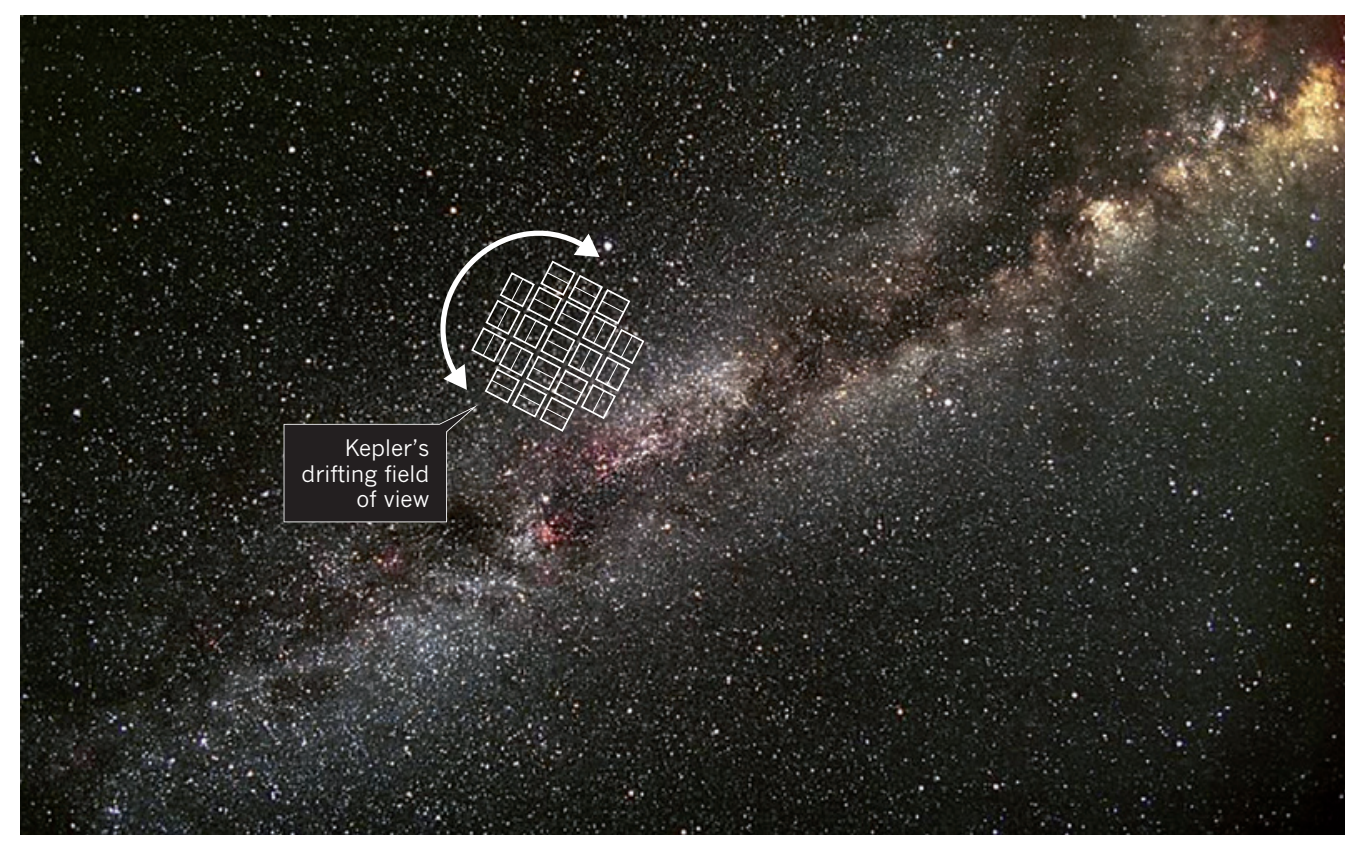

Kepler's field of view is now drifting because of a failure of two of its four reaction wheels.

ASTRONOMY

NASA ponders
Kepler's future

\section{Spacecraft could continue to hunt for planets - or take on alternative tasks, such as asteroid spotting.}

\section{BY RON COWEN}

$\mathrm{N}$ ASA just can't quit Kepler. On 15 August, the agency announced that it would stop trying to revive the failed reaction wheels that gave the planet-hunting telescope its precise pointing ability. That essentially brings an end to the main goal of the 4-year-old mission, which has found 3,548 candidate planets by looking for tiny dips in starlight that indicate a planet's passage, or transit, across that star.

But the agency left room for hope: two weeks earlier, it had asked astronomers to submit ideas by 3 September on how the hobbled spacecraft might still perform good science. Nature has learned about some of the options in the running, out of the dozens of proposals expected.

Ideas range from a survey of potentially hazardous near-Earth objects to a study of Jupiter-sized exoplanets in large orbits. Kepler scientists will sort through the proposals and decide by 1 November which ones, if any, to recommend to NASA headquarters for further review.

To secure funding from the space agency, the Kepler team will have to show that the studies could not be done by other telescopes. This will be no easy task - especially given that engineers are not sure how well Kepler 妥 can perform with just two of its four spin- $\frac{0}{5}$ ning reaction wheels, which act as stabilizing gyroscopes.

"We're in a real quandary," says Kepler principal investigator Bill Borucki at NASA's Ames Research Center in Moffett Field, California. "We just don't know what Kepler can do."

With three working wheels (a fourth was a spare), Kepler was able to exactly counterbalance the persistent push of sunlight, locking on to targets with such precision that light from a particular star always fell on the same tiny fraction of an individual pixel. But the wheels have a history of poor performance, and in July 2012 one failed -

ONATURE.COM For more on Kepler and its discoveries, see: go.nature.com/8pmjuf followed by another in May (see go.nature. com/4w1ufr). Although the craft's thrusters can still act as a crude version of a third wheel, 